\title{
World Journal of Pediatric dog bite injuries in the USA: a
Pediatric Surgery systematic review
}

Kelli Nicole Patterson (1) , Kyle Z Horvath, Peter C Minneci, Rajan Thakkar, LeeAnn Wurster, Dana L Noffsinger, Tran Bourgeois, Katherine J Deans

To cite: Patterson KN, Horvath KZ, ABSTRACT

Minneci PC, et al. Pediatric dog bite injuries in the USA: a systematic review. World Jnl Ped Surgery 2022;5:e000281. doi:10.1136/wjps-2021-00028 - Additional supplemental material is published online only. To view, please visit the journal online (http://dx.doi.org/10.1136/ wjps-2021-000281).

Received 4 March 2021 Accepted 1 September 2021

\section{Check for updates}

(c) Author(s) (or their employer(s)) 2022. Re-use permitted under CC BY-NC. No commercial re-use. See rights and permissions. Published by BMJ.

Center for Surgical Outcomes Research and Department of Surgery, Nationwide Children's Hospital, Columbus, Ohio, USA

Correspondence to Dr Katherine J Deans; Katherine. deans@nationwidechildrens.org
Introduction Dog bites are one of the leading causes of non-fatal emergency room visits in children. These injuries not only cause physical harm but can lead to long-term psychological stress. This study evaluated the current literature related to pediatric dog bite injuries to identify research gaps which should be prioritized to improve a major public health concern.

Methods We performed a keyword search of PubMed, Scopus, and OVID Medline databases (January 1980March 2020) for all published studies focused on dog bite injuries in the pediatric population ( $\leq 18$ years of age) using the Preferred Reporting Items for Systematic Reviews and Meta-Analyses.

Results Out of 1859 abstracts screened, 43 studies involving 86880 patients were included. Twenty-nine studies were retrospective chart reviews characterizing the epidemiology of dog bites and their associated treatment outcomes; six were prospective cohort studies; two were cross-sectional studies; and six were experimental studies. Synthesized results demonstrate that children $<9$ years of age suffer the greatest burden of injuries, with children $<6$ years of age at higher risk of more severe injuries involving the head, neck, and face.

Conclusion Studies analyzing the prevention or psychosocial consequences of dog bites injuries are needed.

\section{INTRODUCTION}

Dog bite injuries are consistently one of the leading causes of non-fatal emergency room visits in children. ${ }^{1-3}$ According to data published by the American Pet Products Association in 2018, there were an estimated 89.7 million dogs owned as pets in the USA, with $50 \%$ of US households owning at least one dog in 2020. ${ }^{4}$ Dog bite injuries in children represent a major public health concern with the estimated lifetime risk of a child being bitten by a dog at $>50 \%$. $^{2}$

Evidence supports that most dog bites occur during the summer months and affect younger children, typically less than 9 years old. ${ }^{2-6} \mathrm{~A}$ majority of dog bites are a result of the child's own pet, and within their own home. ${ }^{7-10}$ The significant risk of children being bitten by a dog paired with the increasing prevalence of US households owning dogs demonstrates the necessity for solutions to this public health problem and may require more robust efforts be put toward education and prevention. ${ }^{24}$ At the same time, these injuries may have a significant psychological impact on patients, as trauma sustained during childhood has been shown not only to affect development but also to pose long-term mental health effects. ${ }^{11}$ This may be an important consideration for clinicians caring for these patients. We performed a systematic literature review to: (1) evaluate the current evidence related to pediatric dog bite injuries and (2) identify gaps still missing in the research, possibly in the realm of education, prevention, policy, psychosocial effects, etc. Investigation of these knowledge gaps may improve a public health concern and impact a substantial population.

\section{METHODS \\ Protocol}

The protocol for this review was drafted according to the standards established by the Preferred Reporting Items for Systematic Reviews and Meta-Analyses (PRISMA) and is not registered. ${ }^{12} 13$

\section{Eligibility criteria}

This study was performed at Nationwide Children's Hospital, a tertiary pediatric trauma center, in Columbus, Ohio. A database search was performed to identify published research articles focusing on dog bite injuries in the pediatric population ( $\leq 18$ years of age) from January 1980 to March 2020. PubMed, Scopus, and OVID Medline databases were used to identify studies. The search term used were "child" OR "pediatric" AND "dog" AND "bite" AND "injury." The review followed PRISMA guidelines with two reviewers categorizing the final inclusion of eligible studies and extracted data with a third reviewer adjudicating discordance. Articles were included based on the following criteria: being a US-based original research study, printed in English, readily available in full text, and 
having a study population size $>20 \quad(n>20)$. Articles were excluded if the study population was not specific to children under 19 years of age, if the primary focus of the study was on rabies prevention/therapy, if studies focused on animal bites in general, or if the information was not specific to dog bites but rather to general injury prevention. The reference lists for included articles were searched manually to ensure appropriate inclusion of all relevant articles.

\section{Data charting process}

To standardize data extraction between reviewers, an aggregate list of items to be extracted from each article was established before the literature search began. Data charting was completed using Microsoft Excel, and article references were housed in EndNote.

\section{Data items}

Data were extracted based on the following variables: title, author, journal, year of publication, study design, location of study, study objectives/purpose, sample size, and main findings. Studies also were categorized based on area of focus (ie, epidemiology, education, prevention, psychosocial effects, and other).

\section{Assessment of risk of bias}

Guidelines provided by the Cochrane Handbook for Systematic Reviews of Interventions (Higgins and Green, 2011) were used in the assessment of bias. ${ }^{14}$ The reviewers considered bias at both the systematic review level and at the individual study level. By design, our study introduces bias at the systematic review level by incorporating only US-based studies. This is done to bolster our ability to answer the main study questions of how children in the USA are impacted by dog bites and what gaps can be identified in US population-based research studies. Individual study level bias was assessed qualitatively by looking at each included article's study design and how the data were gathered. Studies using retrospective chart reviews or epidemiological databases were prioritized over studies using self-reported data such as parent surveys. Individual-level bias was also considered with respect to selection bias, blinding of outcome assessments, and selective reporting.

\section{Data analysis plan}

Data were analyzed qualitatively using descriptive data from each included study. Using the data items collected, reviewers synthesized the main findings of included articles to report overlaps and differences across studies. These congruencies and variances allow for accurate reporting on the incidence of dog bites in pediatric populations across the USA, characterization of dog bite injuries to this population, as well as the types of treatment and prevention strategies used to mitigate dog bite injuries.

Main findings then were categorized into overarching categories of focus and graphically displayed via a bar graph to demonstrate where much of the research around dog bite is currently centered. Categories were not set a priori and were not mutually exclusive. Rather, they were dictated by descriptions of research findings from each journal article. Data compilation and generation of graphs were done using Microsoft Excel, V.2010.

\section{RESULTS}

Systematic literature review and study identification

Out of 1859 potentially relevant articles, 1483 abstracts and titles were screened with 43 studies involving 86880 patients meeting final inclusion criteria and being included in the full text analysis (figure 1). Of the 43 included studies, 29 were retrospective chart reviews characterizing the epidemiology of dog bites and their associated treatment outcomes, with 1 using the National Trauma Database..$^{2-6} 89$ 15-36 Six studies were prospective cohort studies, ${ }^{737-41}$ two were cross-sectional studies, ${ }^{42} 43$ and six were experimental studies (five focused on educational/prevention interventions for children and adults and one focused on prophylactic antibiotic therapy) (online supplemental table 1). ${ }^{1044-48}$ Only 9 of the 43 studies had a behavioral health component incorporated into the study design or discussion sections. ${ }^{71619} 3842-46$

\section{Dog bite incidence and cost}

From 2001 to 2017, there was a clinically significant decrease of $34 \%$ in dog bite injuries among children, adolescents, and young adults aged 0-19 years of age. However, during that time period, dog bite injuries still accounted for nearly 2.5 million emergency department (ED) visits in the pediatric population. ${ }^{3}$ Annually, dog bite injuries in this population account for more than 100000 ED visits and more than 10000 hospital admissions, with a mean length of stay of 2.5 days. ${ }^{34}$ In 2015 , dog bites accounted for more than $66 \%$ of all homeowner insurance liability claims, totaling more than $\$ 570$ million in paid claims. ${ }^{49}$ All of these facts account for the major financial burden of these injuries.

\section{Dog bite injury characteristics and treatment}

Children 0-9 years of age suffer the greatest burden of injuries in the pediatric population (0-19 years), accounting for more than $80 \%$ of injuries, while those under 6 years of age account for approximately half of all cases. ${ }^{3415283233}$ Children $<6$ years of age are also at a substantially increased risk of bites to the head, neck, and face region, often resulting in more severe injuries which more frequently require operative repair. ${ }^{2459152835}$

A study analyzing the national trauma data bank (NTDB) registry reported that over $70 \%$ of cases with an Abbreviated Injury Scale $\geq 3$ occurred in patients 0-5 years of age. ${ }^{33}$ The NTDB data also showed that children $0-12$ years of age accounted for $95 \%$ of all injuries that occurred in the home. The body region injured and location where the injury occurred are inversely proportional with age. Younger children (0-12 years) are more likely 
Identification of studies via keyword search of PubMed, Scopus, and OVID Medline databases with search terms: "Child/pediatric" and "dog" and "bite" and "injury/injuries"

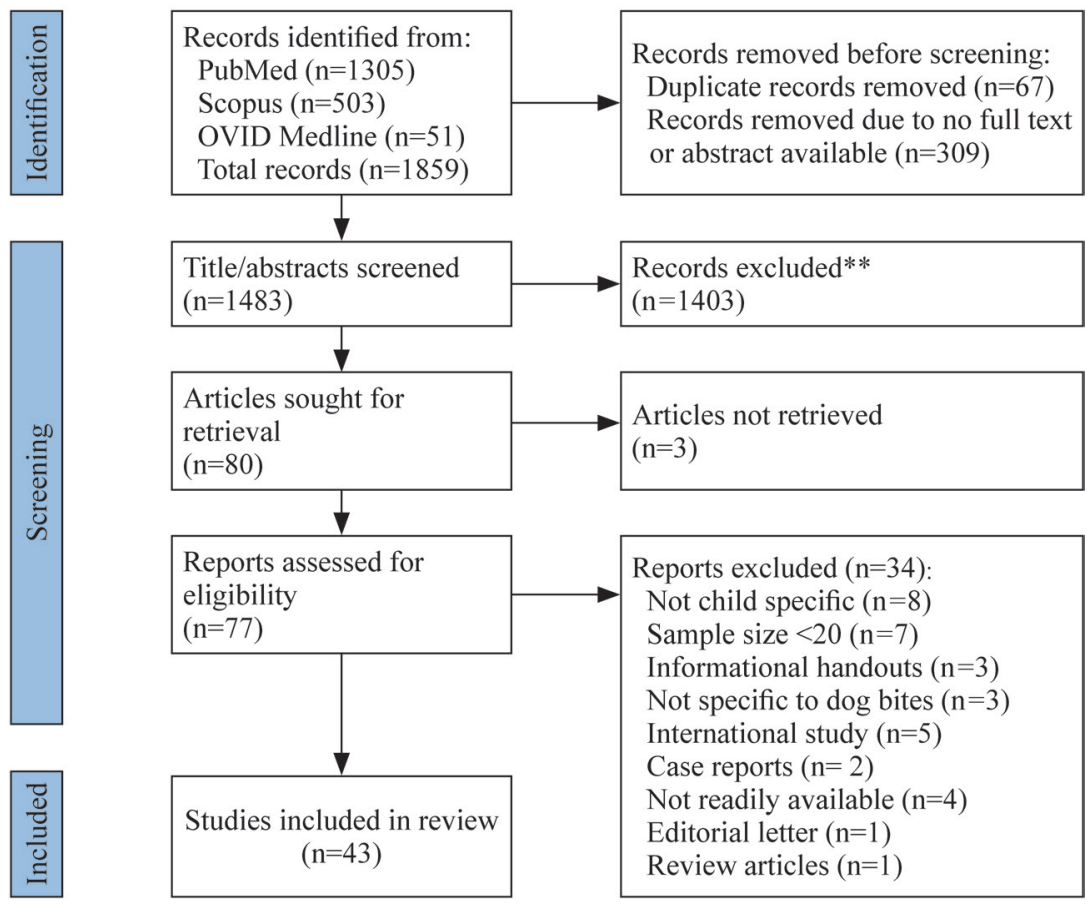

Figure 1 PRISMA flow diagram to determine final inclusion. From: Page et al. ${ }^{13}$ PRISMA, Preferred Reporting Items for Systematic Reviews and Meta-Analyses.

to be bitten in the head, neck, or face region inside the home. Whereas, as children get older, they tend to be bitten on their extremities and outside of the home more frequently. ${ }^{33}$

After the injury occurs, there are various algorithms discussed in the literature to guide treatment recommendations, but most injuries do not necessitate operative repair requiring general anesthesia, but rather, involve irrigation and/or primary closure with procedural sedation or local anesthetic. ${ }^{21} 2433$ Though varying reports exist in the literature, overall, between one-third and one-half of patients with dog bite injury require some form of procedural repair. ${ }^{48} 34$ Operative repair is far less frequently required but seen most in children $<5$ years old, as the severity of their injuries is greater. ${ }^{2462124283436}$

\section{Circumstances surrounding dog bite injury}

Younger children ( $\leq 5$ years old) were more likely to be bitten by their family pet or a dog familiar to them. ${ }^{5-7} 10$ 18-21 323741 These bites most often occurred in the home, during positive interactions initiated by the child (petting or playing with the dog), and as a result of resource (food or toys) guarding by the dog. ${ }^{5-7} 19203239$ Older children were more often bitten by dogs unfamiliar to them while being active and without interaction with the dog, often in response to territory guarding. ${ }^{719}$ More than half of dogs were categorized as being provoked prior to biting, and one study specifically demonstrated that a majority of the examined dogs had not previously bitten a child and had completed obedience training prior to the bite..$^{5-71937}$

\section{Dog breeds}

Seven studies specifically investigated and identified dog breeds as part of their analyses. ${ }^{691517252830}$ Often only a fraction of dogs involved in a bite or attack not taking place in the home are identified. Additionally, due to the difficulty in determining a dog's true genetics, most are defined as mixed breed, leading to a variety of breeds implicated in bite incidents. The tendency of a dog to bite is also known to be a combination of genetic predisposition, early socialization to people, training or maltreatment, the quality of supervision, and behavior of the victim. ${ }^{50}$ After reviewing patient/family reports in the medical chart, Golinko et al identified 46 breeds in $31 \%$ of their cases. Out of $1616 \mathrm{dog}$ bites, the three most prevalent were found to be Pit Bulls (also identified as Staffordshire Bull Terrier, American Staffordshire Terrier, or Bull Terrier, $38.5 \%$ ), mixed breeds (Pit Bull mixes, Labrador mixes, Pit Bull/Labrador mixes, $13 \%$ ), and Labradors $(8.1 \%) .{ }^{28}$ Chen et al identified 58 breeds in $68 \%$ (366) of cases, with the most common breeds being mixed (23\%), Labrador Retriever (13.7\%), Rottweiler (4.9\%), and German Shepherd (4.4\%). ${ }^{6}$ Sribnick et al identified dog breed in $55 \%$ of cases where Pit Bulls were the most common $(50.4 \%)$, followed by Rottweilers $(12.2 \%)$, Labradors $(8.4 \%)$, German Shepherds (5.3\%) and Chows $(4.6 \%) .{ }^{9}$ In 40 dog bite attacks, the most common breeds 
$(n=15)$ were German Shepherd and German Shepherd mix, and the dogs involved in fatal attacks were two Rottweilers, one Husky, and one Akita. ${ }^{17}$ In a study using a local country health department, a listed dog breed was available for $54 \%$ of cases with $22.5 \%$ classified as mixed breed. The most frequently reported dog breeds who had bitten (and were not classified as mixed) were Pit Bull (27.2\%), German Shepherd (10.5\%), Labrador Retriever $(7.2 \%)$, Boxer (4.6\%), Rottweiler (3.9\%), Beagle (3.3\%), Jack Russell (2.9\%), Bulldog (2.9\%), Chihuahua (2.6\%), Husky (2.3\%), Golden Retriever (2.3\%), Dachshund (2.2\%), Mastiff (1.9\%), Shih-tzu (1.9\%), Poodle (1.6\%), and Cocker Spaniel (1.5\%). Eight additional breeds each representing $<1.5 \%$ of bites were also identified (Yorkshire Terrier, Great Dane, Australian Shepherd, Doberman, Boston Terrier, Akita, Collie).$^{30}$ Though these studies identified dog breeds involved in bite injuries, it is difficult to draw conclusions on the involvement of specific breeds in pediatric dog bites as the overall underlying dog population is not available for comparison, and breed stratification is not possible.

\section{Education and prevention}

Studies focused on prevention strategies analyzed educational programs designed to increase knowledge and awareness of safe behavior with dogs in both children and family members. ${ }^{42-46}$ There was consensus that children and parents who engaged in prevention education programs increased their knowledge of safe dog behavior for children. These studies indicated that children older than 4 years of age can learn basic knowledge about how to behave more safely around dogs.

\section{Study characteristics}

Very few articles included in our analysis explored dog bite prevention methodology and the psychosocial effects of dog bites on the pediatric arena. Among our review of current literature, 36 articles focused on dog bite characterization, 5 focused on education, 1 on a combination of dog bite characterization and education, 1 on effects of dog bites on the victim, and 1 on psychosocial aspects (figure 2). The topic of dog bite characterization consisted of the following subtopics: incidence and epidemiology of dog bites where descriptions of incidence by age and gender were provided; rate of dog bites within the USA, defined as when or how often an attack occurred; location of dog bite on the body, defined as which body part was affected by the bite; geographical comparison, defined as comparison of different geographical locations within the USA where dog bites were found to be prevalent; treatment of $\operatorname{dog}$ bite/ management, defined as location where treatment was sought (emergency room, operating room); risk, defined as ORs provided for risk of injury; injury setting, defined as surround environment where dog bites occurred (this also included whether guardian or parental supervision was present or not); dog breed or type, defined as the type or breed of dog that caused the attack; events leading

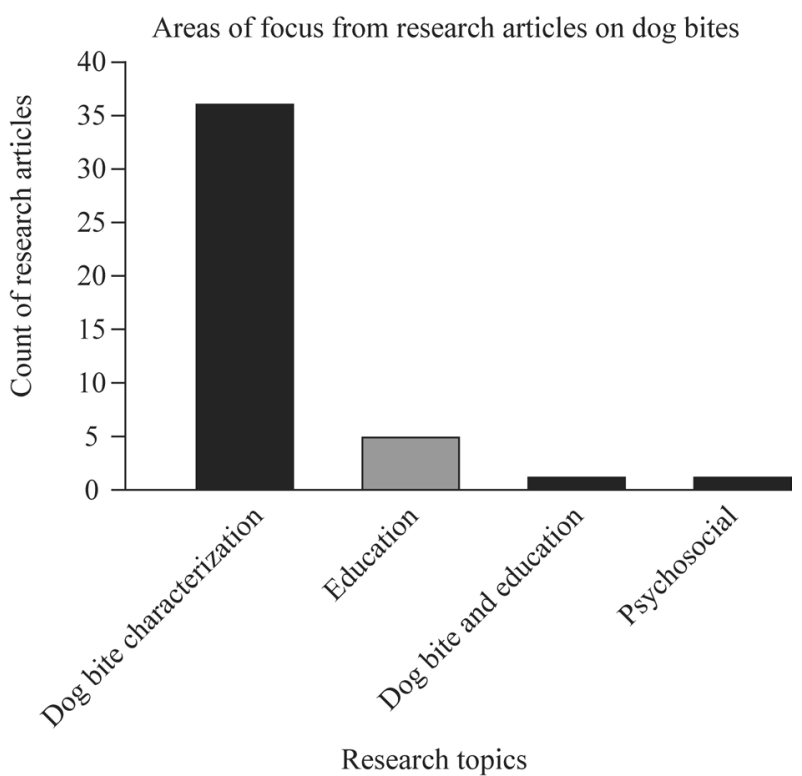

Figure 2 Breakdown of research articles on dog bite by main areas of focus.

up to the attack, defined as whether or not dogs were provoked; cost, defined as total cost of care related to dog bite injury; and obedience training, defined as behavioral screening of dogs and common stimuli for aggression in dogs. The topic of education centered mostly around programs aimed at bringing about knowledge and awareness of dogs as well as focusing on the behavior of children affected by dog bite injuries. Among the five articles that touch on education, one focused on behavior of children affected by dog bite injuries, one focused on knowledge of dog bite prevention strategies, and three focused on awareness. Among articles with a focus on dog bite characterization, the majority focused on incidence and epidemiology $(n=12)$, location of dog bite on the body $(n=14)$, and treatment and management of dog bite $(n=16)$ (figure 3$)$. When evaluating the geographical distribution of studies, they were found to span the USA, with the exception of five studies which used national databases. Based on their main areas of focus, studies on education and psychosocial aspects were performed in the Eastern USA (figure 4).

\section{DISCUSSION}

A systematic literature review was performed to determine existing research gaps related to pediatric dog bite injury. Our goal was to identify the areas that should be prioritized to address this major public health concern, as dog bites remain a leading cause of injury in children. ${ }^{3}$ We found that most publications focus on epidemiologic data elements, injury patterns, and treatment. In our review, very little published material addresses the prevention of, or psychosocial consequences, associated with pediatric dog bites. Studies analyzing these aspects are needed as pet ownership continues to grow and the 
Specific areas of focus for research articles on dog bites

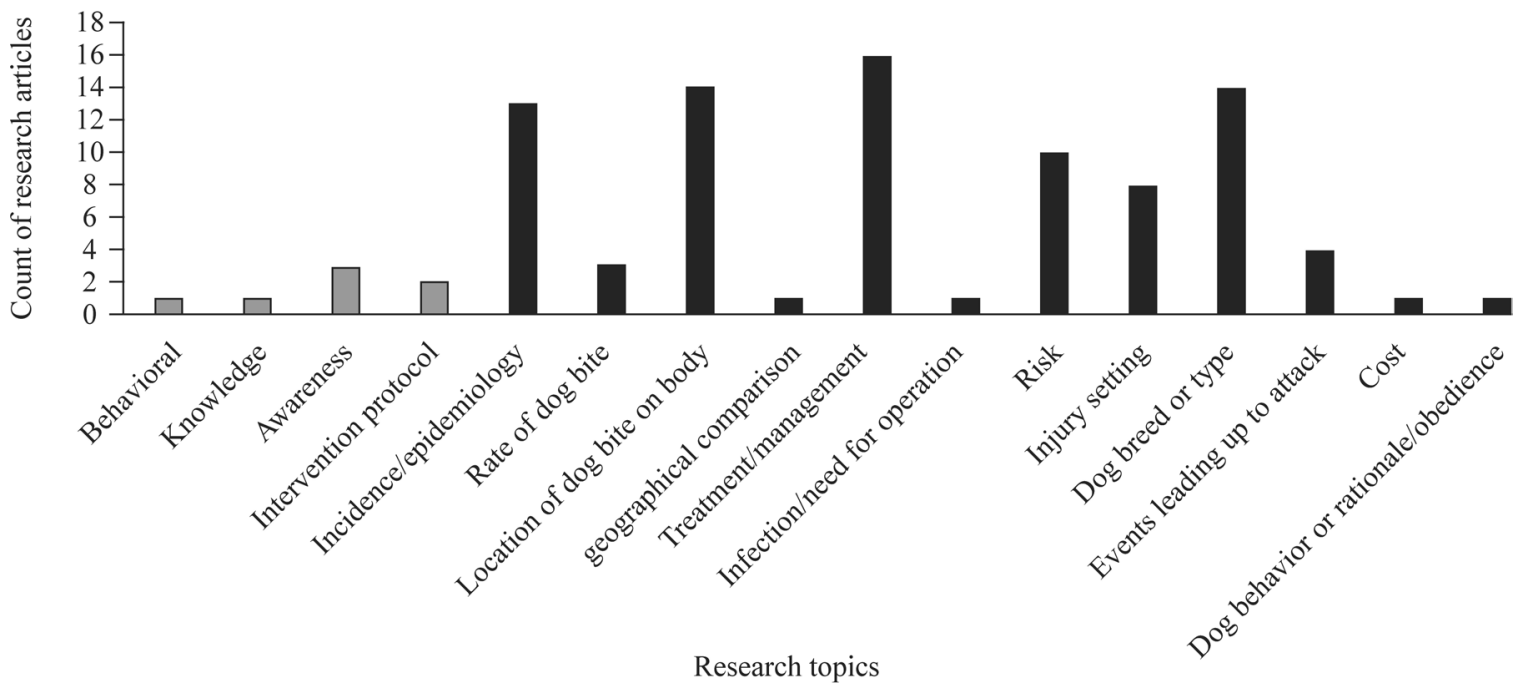

Figure 3 Breakdown of research articles on dog bite by main areas of focus. Gray bars depict subtopics for education while black bars represent subtopics for dog bite characterization as seen in figure 2 .

likelihood of children interacting with dogs in their daily lives becomes inevitable.

\section{Education and prevention}

Five of the 43 studies within our review did focus on dog bite education and prevention in children using an experimental design. It is reasonable to suggest that education of either the child or parent would play a large role in preventing dog bite injury, but as evidenced by our review, it is rarely addressed by healthcare providers or research. ${ }^{2}$

Though the exact reasons are unknown, experts in the field often attribute the elevated risk of dog bite injury in children to at least three main factors. First, children's misperception, misinterpretation, or ignorance

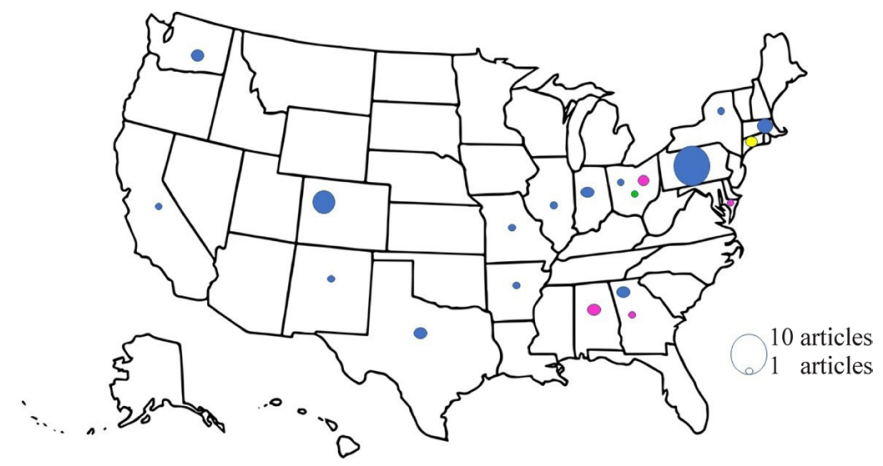

Figure 4 Geographical distribution of dog bite studies by main areas of focus. Adapted for use from Teelion (www. etsy.com/shop/DigitaLion) by TB and KNP. Permission for use was granted. Blue = dog bite characterization; magenta = education; green = psychosocial; yellow = dog bite characterization and education; *National database = dog bite characterization (not shown). The size of each dot correlates with the number of studies which met inclusion from that US state, with the smallest dot representing 1 study and the largest dot representing 10 studies. of a dog's perspective due to an underdeveloped theory of mind contributes to stressed or frustrated dogs and leads to aggression. Second, children lack cognitive skills required to recognize and understand how to behave appropriately around dogs. Finally, children being physically shorter in stature likely leads to increased prevalence of bites to the head/neck region often requiring more aggressive intervention than those to the limbs. ${ }^{446}$

Schwebel et al published two prominent prospective studies in 2012 and in 2016 which worked to enhance knowledge on the prevention of dog bite injuries through educational programs. ${ }^{44} 46$ In 2011, an interactive computer program (The Blue Dog), dollhouse simulations, and live dog interactions were applied to children 3-6 years old. The goals of the study were to improve children's recognition knowledge about safe and unsafe interactions, improve recall of safe and dangerous behavior in a dollhouse simulation, and decrease risky behavior while engaging with a live dog. Results showed improvement in basic knowledge of how to behave more safely with dogs, but children did not recall lessons from the dollhouse simulations nor implement safer behaviors when exposed to the live dog. ${ }^{46}$

While these results may seem surprising, they highlight an important topic which researchers have struggled with for years: identifying necessary approaches in transitioning knowledge into actual health behavior change. ${ }^{46}$ This, paired with the complexities related to child development, calls attention to the need for age-specific strategies being implemented when it comes to effective education. Another possibility suggested by past research is the idea of 'optimism bias', in which children gain confidence that dogs are 'safe' because their initial exposure produced no negative effect, and they partake in riskier interactions during the subsequent encounter. ${ }^{4-46}$ To address this idea, in a 2016 study, Schwebel et al introduced a second computer-based program to children 
and performed similar knowledge-based quizzes and dollhouse simulations. However, this time they only introduced the live dog interaction after the modules were completed, whereas children interacted with the live dog both before and after their module education in the previous experiment. Again, children demonstrated a significant gain in knowledge and recognition of safe behavior but did not improve their scores related to dollhouse simulation or live dog interaction. ${ }^{44}$ To truly succeed in preventing dog bite injuries, it is necessary to identify how to effectively educate the pediatric population and incorporate this knowledge into new learned behaviors.

Another aspect to consider to fully address the prevention of dog bite injury is a caregiver's lack of knowledge on the topic. In general, dog owners have shown a lack of familiarity about features associated with dog aggression toward children. In Tucson, only two-thirds of the 126 dog-owning parents surveyed believed that infants were at risk of a fatal dog bite. Two-thirds also felt it was safe to leave a 4-year-old child unattended with a dog, and most did not realize the increased prevalence of $\operatorname{dog}$ bites among children in general. ${ }^{47}$ In the same study, 77 pediatricians were surveyed. Only $17 \%$ reported regularly educating parents on pet-related injuries and $14 \%$ felt that education in the office was not worthwhile. ${ }^{51}$ In contrast, in a study of 455 families in a Denver pediatric practice, $77 \%$ of parents believed that dog bite prevention was an important discussion to have with a physician. ${ }^{41}$ In an ED survey of 48 caregivers with dogs in the household, $56 \%$ reported that their dog had not been spayed/neutered, and 21\% reported leaving their child alone with the $\operatorname{dog}{ }^{47}$ A case-control study by Gershman et al demonstrated that biting dogs were more likely to be German Shepherd and Chow Chow breeds, male, and unneutered. Authors strongly suggest that owners, through their selection and treatment of dogs, may be able to reduce the likelihood that a dog will bite in the future. Additionally, they urge pediatricians to advise parents that failure to neuter a dog and selecting a male dog of specific breed may increase the chances of a bite in the household. ${ }^{52}$

Resolving the public health concern related to dog bites must also be undertaken, and there is currently no literature that has done this. It is important to gain insight on the policies and legislation that are in place in the cities and surrounding communities we live in. Public health law research directed at correlating whether the law has an impact on pediatric dog bite injury would allow for the opportunity to guide lawmakers in the changes and decisions they put forth based on this issue. Additionally, it allows us to educate the public about the laws governing dog ownership and work to prevent dog bites from a novel angle.

A gap clearly remains in successfully translating pediatric knowledge into behavior and how interactions with dogs can impact beliefs about injury vulnerability. ${ }^{44}$ Innovative measures will be necessary to address these gaps and produce successful prevention strategies. Additionally, the caregiver must be provided with the necessary education and exhibit the willingness to participate in a safe, positive relationship between themselves, their child and their dog.

\section{Psychosocial burdens related to dog bite injury}

When considering the psychosocial burden placed on children following a dog bite, only eight studies within our review included a behavioral health component either in the study design or discussion. With minimal research related to this topic, we must first question whether a child's psychosocial well-being is affected and then identify how and to what degree. With 89.7 million dogs owned as pets in the USA, the chances of a child encountering a dog after their injury are extremely high, if not inevitable. By putting our efforts toward identifying how to alleviate psychosocial disturbances caused by a dog bite injury, we would hope to return these children to some sense of normalcy in their daily lives.

In one of the more significant behavioral studies done by Boat et al, ${ }^{38}$ the parents of 34 patients aged 0-16 years old who presented to the ED with 'dog bite' were contacted for a 4-week follow-up phone interview. In that interview, information was obtained pertaining to: bite incident specifics, further medical/psychological care needed related to the dog bite, contact with additional legal or enforcement agencies, changes in the child's behavior, changes in the parental concerns about themselves and their children after the dog bite, and parent feedback on the value of having additional services available. At least one new concerning behavior was observed in over $70 \%$ of children, with the five most prevalent behaviors seen in $21 \%-29 \%$ of patients. These included: talking a lot about the incident, being fearful of dogs, avoiding dogs, being anxious or worried about seeing doctors/going to the hospital, being fearful, and having bad dreams/nightmares. When parents were interviewed about the incident, $86 \%$ endorsed changes in their concerns and feelings about themselves and their children, $59 \%$ felt guilty they could not protect the child, $59 \%$ worried about the child's scars, and $44 \%$ were angry and fearful for their child's safety. When parents were asked whether their child would benefit from interventions to help with their fears, $50 \%$ felt it would be helpful and $85 \%$ felt that the best timing for families to get extra help would be in the ED or physician's office. ${ }^{38}$

By more thoroughly investigating the specific psychological effects that burden dog bite patients, we may be able to close this clinical gap and bring awareness to institutions of the urgent need for mental health services in this patient population. As clinicians, we must identify how to safely introduce these victims back into a life where dogs exist in order to return them to a functional daily existence. 


\section{Limitations of the study}

This systematic literature review has several limitations. First, we used the most relevant medical databases (PubMed, Medline, Scopus) for this study and did not include other lower yield databases. This could have allowed us to miss additional studies. Additionally, we excluded studies of patient populations $\leq 20$ in order to eliminate the review of case reports and case series, which are often of low statistical power and would not necessarily reflect the true epidemiology of dog bites, but rather focus on unique patient experiences or treatment modalities. It is possible though, that some intervention studies may have been screened out using this exclusion. These limitations may contribute to selection bias and possible under-reporting or over-reporting of findings within the literature.

In conclusion, our systematic review of published literature on pediatric dog bite injury yielded thorough coverage of the epidemiology, injury pattern, and treatments associated with dog bites. Key evidence gaps remain in preventing dog bites from occurring and addressing the psychosocial damage inflicted on the child. To make the biggest impact on what remains a major public health concern, we need to direct research efforts and innovations towards addressing these evidence gaps. It is important to advocate for state and county laws which improve injury prevention in dog attacks, to necessitate parental education at the time of obtaining a dog, and to support the use of educational initiatives led by veterinarians and primary care physicians.

\section{Twitter Kelli Nicole Patterson @kellinicole87}

Contributors KNP contributed to conceptualization, data curation, forma analysis, investigation, validation, visualization, writing (original draft), writing (review and editing). KZH contributed to conceptualization, data curation, investigation, validation, visualization, writing (original draft), writing (review and editing). PCM contributed to conceptualization, data curation, formal analysis, investigation, validation, visualization, writing (original draft), writing (review and editing). RT contributed to conceptualization, investigation, validation, visualization, writing (original draft), writing (review and editing). LAW contributed to conceptualization, data curation, validation, visualization, writing (review and editing). DLN contributed to conceptualization, data curation, visualization, writing (review and editing). TB contributed to conceptualization, data curation, formal analysis, investigation, validation, visualization, writing (original draft), writing (review and editing). KJD contributed to conceptualization, data curation, formal analysis, investigation, validation, visualization, writing (original draft), writing (review and editing).

Funding The authors have not declared a specific grant for this research from any funding agency in the public, commercial or not-for-profit sectors.

Map disclaimer The depiction of boundaries on this map does not imply the expression of any opinion whatsoever on the part of BMJ (or any member of its group) concerning the legal status of any country, territory, jurisduction or area or of its authorities. This map is provided without any warranty of any kind, either express or implied.

Competing interests None declared.

Patient consent for publication Not required.

Ethics approval Not required.

Provenance and peer review Not commissioned; externally peer reviewed.

Data availability statement № data are available.

Open access This is an open access article distributed in accordance with the Creative Commons Attribution Non Commercial (CC BY-NC 4.0) license, which permits others to distribute, remix, adapt, build upon this work non-commercially, and license their derivative works on different terms, provided the original work is properly cited, appropriate credit is given, any changes made indicated, and the use is non-commercial. See: http://creativecommons.org/licenses/by-nc/4.0/.

ORCID iD

Kelli Nicole Patterson http://orcid.org/0000-0003-4764-2927

\section{REFERENCES}

1 Centers for disease control and prevention, National center for injury prevention and control. Web-based injury statistics query and reporting system (WISQARS), 2020. Available: https://www.cdc.gov/ injury/wisqars/index.html [Accessed 28 Oct 2020].

2 McLoughlin RJ, Cournoyer L, Hirsh MP, et al. Hospitalizations for pediatric dog bite injuries in the United States. J Pediatr Surg 2020;55:1228-33.

3 Basco AN, McCormack ER, Basco WT. Age- and sex-related differences in nonfatal dog bite injuries among persons aged 0-19 treated in hospital emergency departments, United States, 20012017. Public Health Rep 2020;135:238-44.

4 Cook JA, Sasor SE, Soleimani T, et al. An epidemiological analysis of pediatric dog bite injuries over a decade. J Surg Res 2020;246:231-5.

5 Chun YT, Berkelhamer JE, Herold TE. Dog bites in children less than 4 years old. Pediatrics 1982;69:119-20.

6 Chen HH, Neumeier AT, Davies BW, et al. Analysis of pediatric facial dog bites. Craniomaxillofac Trauma Reconstr 2013;6:225-31.

7 Reisner IR, Nance ML, Zeller JS, et al. Behavioural characteristics associated with dog bites to children presenting to an urban trauma centre. Inj Prev 2011;17:348-53.

8 Calkins CM, Bensard DD, Partrick DA, et al. Life-Threatening dog attacks: a devastating combination of penetrating and blunt injuries. J Pediatr Surg 2001;36:1115-7.

9 Sribnick EA, Sarda S, Sawvel MS, et al. Dog bite injuries in children: clinical implications for head involvement. Trauma 2016;18:210-5.

10 Boenning DA, Fleisher GR, Campos JM. Dog bites in children: epidemiology, microbiology, and penicillin prophylactic therapy. Am $J$ Emerg Med 1983;1:17-21.

11 Oh DL, Jerman P, Silvério Marques S, et al. Systematic review of pediatric health outcomes associated with childhood adversity. BMC Pediatr 2018;18:83.

12 Liberati A, Altman DG, Tetzlaff J, et al. The PRISMA statement for reporting systematic reviews and meta-analyses of studies that evaluate health care interventions: explanation and elaboration. $J$ Clin Epidemiol 2009;62:e1-34.

13 Page MJ, McKenzie JE, Bossuyt PM, et al. The PRISMA 2020 statement: an updated guideline for reporting systematic reviews. BMJ 2021;372:n71.

14 Higgins JPT, Green S. Cochrane Handbook for systematic reviews of interventions, version 5.1.0: the Cochrane collaboration. Available: https://training.cochrane.org/handbook

15 Alizadeh K, Shayesteh A, Xu ML. An algorithmic approach to operative management of complex pediatric dog bites: 3-year review of a level I regional referral pediatric trauma Hospital. Plast Reconstr Surg Glob Open 2017;5:e1431.

16 Beck AM, Jones BA. Unreported dog bites in children. Public Health Rep 1985;100:315-21.

17 Brogan TV, Bratton SL, Dowd MD, et al. Severe dog bites in children Pediatrics 1995;96:947-50.

18 Bernardo LM, Gardner MJ, Amon N. Dog bites in children admitted to Pennsylvania trauma centers. Int J Trauma Nurs 1998;4:121-7.

19 Reisner IR, Shofer FS, Nance ML. Behavioral assessment of childdirected canine aggression. Inj Prev 2007;13:348-51.

20 Mitchell RB, Nañez G, Wagner JD. Dog bites of the scalp, face, and neck in children. Laryngoscope 2003;113:492-5.

21 Daniels DM, Ritzi RBS, O'Neil J, et al. Analysis of nonfatal dog bites in children. J Trauma 2009;66:S17-22.

22 Kaye AE, Belz JM, Kirschner RE. Pediatric dog bite injuries: a 5-year review of the experience at the children's Hospital of Philadelphia. Plast Reconstr Surg 2009;124:551-8.

23 Bjork A, Holman RC, Callinan LS, et al. Dog bite injuries among American Indian and Alaska native children. J Pediatr 2013;162:1270-5.

24 Wu PS, Beres A, Tashjian DB, et al. Primary repair of facial dog bite injuries in children. Pediatr Emerg Care 2011;27:801-3.

25 O'Brien DC, Andre TB, Robinson AD, et al. Dog bites of the head and neck: an evaluation of a common pediatric trauma and associated treatment. Am J Otolaryngol 2015;36:32-8.

26 Speirs J, Showery J, Abdou M, et al. Dog bites to the upper extremity in children. J Paediatr Child Health 2015;51:1172-4. 
27 Sadiq MAA, Corkin F, Mantagos IS. Eyelid lacerations due to dog bite in children. J Pediatr Ophthalmol Strabismus 2015;52:360-3.

28 Golinko MS, Arslanian B, Williams JK. Characteristics of 1616 consecutive dog bite injuries at a single institution. Clin Pediatr 2017;56:316-25

29 Bratton EM, Golas L, Wei LA, et al. Ophthalmic manifestations of facial dog bites in children. Ophthalmic Plast Reconstr Surg 2018;34:106-9.

30 Ramgopal S, Brungo LB, Bykowski MR, et al. Dog bites in a U.S. County: age, body part and breed in paediatric dog bites. Acta Paediatr 2018;107:893-9.

31 Bykowski MR, Shakir S, Naran S, et al. Pediatric dog bite prevention: are we Barking up the wrong tree or just not Barking loud enough? Pediatr Emerg Care 2019;35:618-23.

32 Abraham JT, Czerwinski M. Pediatric dog bite injuries in central Texas. J Pediatr Surg 2019;54:1416-20.

33 Fein J, Bogumil D, Upperman JS, et al. Pediatric dog bites: a population-based profile. Inj Prev 2019;25:290-4.

34 Smith AM, Carlson J, Bartels AB, et al. Characteristics of dog bites in Arkansas. South Med J 2018;111:494-500.

35 Hurst PJ, Hoon Hwang MJ, Dodson TB, et al. Children have an increased risk of periorbital dog bite injuries. J Oral Maxillofac Surg 2020;78:91-100.

36 Essig GF, Sheehan CC, Niermeyer WL, et al. Treatment of facial dog bite injuries in the emergency department compared to the operating room. OTO Open 2019;3:2473974X1985832.

37 Eppley BL, Schleich AR. Facial dog bite injuries in children: treatment and outcome assessment. J Craniofac Surg 2013;24:384-6.

38 Boat BW, Dixon CA, Pearl E, et al. Pediatric dog bite victims: a need for a continuum of care. Clin Pediatr 2012;51:473-7.

39 Bernardo LM, Gardner MJ, Rosenfield RL, et al. A comparison of dog bite injuries in younger and older children treated in a pediatric emergency department. Pediatr Emerg Care 2002;18:247-9.

40 Avner JR, Baker MD. Dog bites in urban children. Pediatrics 1991;88:55-7.
41 Lauer EA, White WC, Lauer BA. Dog bites. A neglected problem in accident prevention. Am J Dis Child 1982;136:202-4.

42 Dixon CA, Mahabee-Gittens EM, Hart KW, et al. Dog bite prevention: an assessment of child knowledge. J Pediatr 2012;160:337-41.

43 Dixon CA, Pomerantz WJ, Hart KW, et al. An evaluation of a dog bite prevention intervention in the pediatric emergency department. $J$ Trauma Acute Care Surg 2013;75:S308-12.

44 Schwebel DC, Li P, McClure LA, et al. Evaluating a website to teach children safety with dogs: a randomized controlled trial. Int J Environ Res Public Health 2016;13:1198

45 Schwebel DC, McClure LA, Severson J. Evaluating a website to teach children safety with dogs. Inj Prev 2015;21:e2.

46 Schwebel DC, Morrongiello BA, Davis AL, et al. The blue dog: evaluation of an interactive software program to teach young children how to interact safely with dogs. J Pediatr Psychol 2012;37:272-81.

47 Shields WC, McDonald EM, Stepnitz R, et al. Dog bites: an opportunity for parent education in the pediatric emergency department. Pediatr Emerg Care 2012;28:966-70.

48 Mello MJ, Getz MA, Lapidus G, et al. Innovations in injury prevention education. J Trauma 2007;63:S7-9.

49 Insurance Information Institute. Spotlight on: dog bite liability: insurance information Institute, 2020. Available: https://www.iii. org/article/spotlight-on-dog-bite-liability\#Estimated $\% 20$ Number\% 20and\%20Cost\%20of\%20Dog\%\%2020Bite\%20Claims\% 20Nationwide,\%202003-2019\%20(1) [Accessed 26 Aug 2020].

50 Guidelines for regulating dangerous or vicious dogs. Companion Animals Section and Division of Higher Education Programs [Internet], 2021 [Accessed 12 Jan 1987].

51 Villar RG, Connick M, Barton LL, et al. Parent and pediatrician knowledge, attitudes, and practices regarding pet-associated hazards. Arch Pediatr Adolesc Med 1998;152:1035-7.

52 Gershman KA, Sacks JJ, Wright JC. Which dogs bite? A casecontrol study of risk factors. Pediatrics 1994;93:913-7. 